LSE 'Europe in Question’ Discussion Paper Series

\title{
Parallel Lives: Social Comparison Across
}

\section{National Boundaries}

Jonathan White

LEQS Paper No. 47/2012

January 2012

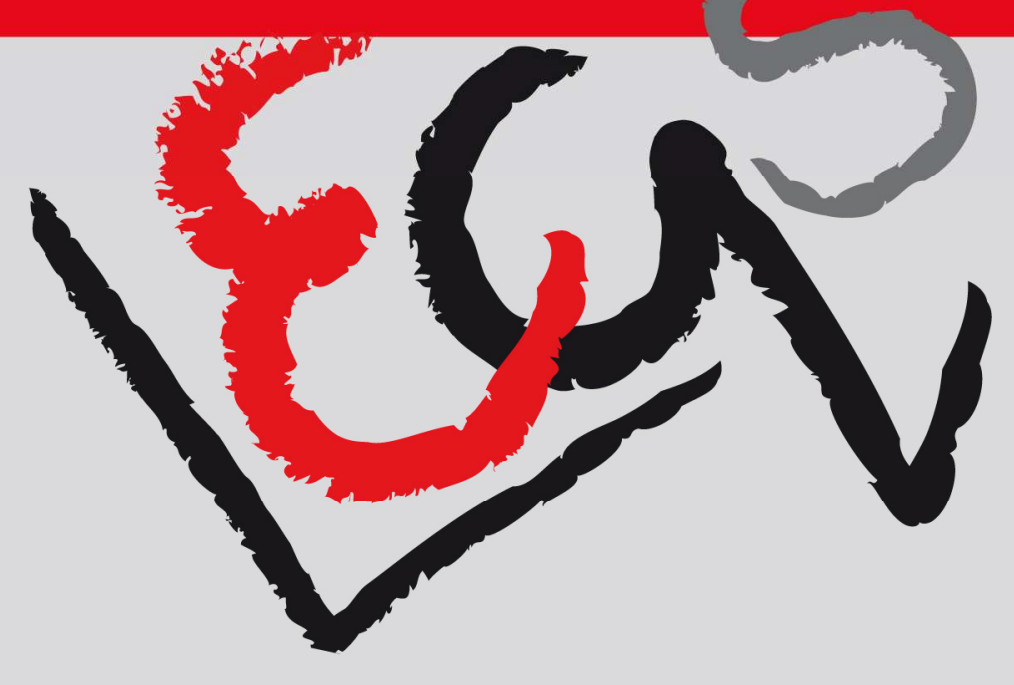




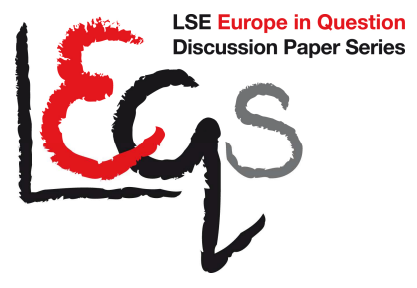

\section{Editorial Board}

Dr. Joan Costa-i-Font

Dr. Vassilis Monastiriotis

Dr. Jonathan White

Ms. Katjana Gattermann

All views expressed in this paper are those of the author and do not necessarily represent the views of the editors or the LSE.

(C) Jonathan White 


\title{
Parallel Lives: Social Comparison
}

\section{Across National Boundaries}

\author{
Jonathan White*
}

\begin{abstract}
The paper presents a distinctive approach to cross-border ties between Europeans. In place of the standard focus on identity or trust, it recommends the study of practices of social comparison, understood as how citizens evoke relevant others for the purpose of situating and evaluating their experiences. The first section offers a conceptual analysis of social comparison, building on and extending social-psychological accounts. The second section shows how the emergence of the European Union presents new opportunities for social comparison. By generating diverse social encounters, new information resources, and an extension in the scope of common legislation, it invites citizens to compare their daily experiences with those of people further afield and to evoke reference groups outside their country of residence. The third section looks at the political significance of these emergent practices, be it for the perception of injustice, the sense of personal misfortune, or the development of new forms of cross-national subjecthood.
\end{abstract}

* London School of Economics

European Institute, Houghton St, London WC2A 2AE, UK

Email: j.p.white@lse.ac.uk 


\section{Table of Contents}

Abstract

1. Introduction

2. Varieties of Social Comparison and their Significance

3. Social Comparison in the Transnational Setting

4. Implications of an Enlarging Scope of Comparison

5. Conclusion

References

\section{Acknowledgements}

The author thanks Adrian Favell and Maurice Fraser for written comments on the paper, and participants of the EU seminar at Sciences Po in Paris for oral feedback in July 2011. The text is forthcoming in Niilo Kauppi (ed.) (2012), A Political Sociology of Europe (Colchester: ECPR Press). 


\section{Parallel Lives: Social Comparison}

\section{Across National Boundaries}

\section{Introduction}

One way to approach the human world is in terms of a distinction between system and social integration. Theorists have made it in various forms, so let us delineate it as follows. System integration evokes a world whose emergence and reproduction is not reducible to the intentions and understandings of individual actors within it. It is the world of structures and institutions, including the market, the law and the industrial-technological complex, all seen from an observer's perspective. Social integration by contrast evokes a world of actors, and of human relations recognisable and meaningful to those immersed in them. It is the world of allegiances, conflicts and mutual concern. ${ }^{1}$ Ultimately, system and social integration may be considered two different methodological responses to the same challenge that of rendering the world and its patterns intelligible - and one need not suppose the existence of two separate spheres. The appeal of the distinction lies in its ability to highlight tensions and contradictions, e.g. between functionality and legitimacy. In contemporary EU scholarship, system integration is the prime focus of various strands of institutionalism in political

\footnotetext{
${ }^{1}$ For the distinction in its original form, see Lockwood 1964, p.371; for overviews of various reworkings, see Mouzelis 2008, Joas and Knöbl 2009, Delanty and Rumford 2005. In European studies, the relation between system and social integration was one of the main themes of debate amongst functionalist, federalist and neo-functionalist observers of post-War Europe as well as interested actors themselves. Often these debates were framed in terms of the relative significance of economic integration on the one hand and political-cultural integration on the other, an articulation liable to create an overly strong distinction between the economic as the domain of material interests and system imperatives and the political-cultural as the domain of beliefs and ideas.
} 
science, legal studies and political economy, where system-evoking notions of 'adaptational pressure', 'goodness of fit' and 'incentive structure' are commonplace. Social integration meanwhile has been attended to in research on European identity, cross-border trust and the EU's politicisation. Perhaps the standard interpretation is that the contemporary European sphere, when approached in terms of system integration, is considerably more densely enmeshed than when approached in terms of social integration, but that this situation cannot persist indefinitely without destabilising consequences indeed, that its consequences may be fatal when the EU hits times of crisis.

This paper addresses social integration primarily, with the aim of exploring one of its less familiar forms - practices of social comparison. Its purpose is to show how changing popular perceptions can be conceptualised differently from the identity problematic commonly favoured in EU studies, and - as a contribution to political sociology and social psychology - to theorise in some detail the structure and wider implications of social comparison. One of the paper's themes however is the interplay between this form of social integration and the wider European context of system integration. Developments associated with the latter - rights to cross-border movement, for instance - provide opportunities and stimuli for new social relations, as well as perhaps depending for their long-term existence on the development and consolidation of these relations.

Social comparison in the sense we shall discuss it entails a human subject's evocation of relevant others for the purpose of a relative appraisal of conditions. It involves positing the existence of those parallel to the self who, as judged against a certain criterion, may be deemed to resemble (more so or 
less so) that self. ${ }^{2}$ These relevant others may be distant in space, and only in some cases encountered. The prospect which institutional developments in Europe raise - especially sharply perhaps, but not unlike wider processes of globalisation - is that relevant others come increasingly to be perceived crossas well as intra-nationally, thus entailing a widening of social horizons as new figures fall within attentive range. Unlike more familiar forms of social integration, such as a convergence of identities, norms and values or a deepening of interpersonal trust, social comparison need not produce generally harmonious social relations. In some cases it may spur a sense of common predicament, and thus the basis for ties of solidarity. In others it may produce an affirmation of difference, prompting indifference or hostility and possibly social upheaval. Accordingly it will have feedback effects for system integration, consolidating it, reforming it, or placing it in question.

Methodologically, social comparison is best treated as an interpretative heuristic - a way of making sense, in idealised form, of how others in turn make sense of the social world. Rather than to postulate hard psychological laws governing beliefs and behaviour, the goal is to suggest patterned ways of thinking which, though likely to recur in some contexts especially, take a variety of forms and can produce more than one outcome, due to the way they combine unpredictably with secondary factors. Social theorists use the concept of mechanism to capture this mix of regularity and indeterminacy (Elster 2007). ${ }^{3} \quad$ Practices of social comparison and their socio-political consequences are usefully approached as such, sensitising us to general tendencies of likely significance whose articulation and impact in the

\footnotetext{
${ }^{2}$ As we shall note, the perception of similarity is only one possible outcome, and even where present it is domain-specific. Parallel lives are not convergent lives - the subjects retain their distinctiveness.

${ }^{3}$ Some approaches to social mechanisms (e.g. Hedström and Swedberg 1998) invoke them as means to give precision to an explanatory account. Here we do not wish to explain determined outcomes - the practices we describe remain half-formed, and their ultimate consequences as yet opaque - but instead to identify some important current trends, to chart future trajectories, and develop the building-blocks from which explanatory accounts might proceed.
} 
particular instance will still need to be analysed by historical, i.e. contextual, means. By elaborating such mechanisms, we sharpen our eye for the trends of the present, and give orientation to future research.

\section{Varieties of Social Comparison and their Significance}

The concept of social comparison has its origins in social psychology (Festinger 1954; see also Masters and Smith 1987; Suls et al. 2002; Guimond 2006). Early discussions presented it as a kind of need, grounded in the functional importance to the individual of accurate self-appraisal. In order to navigate life's demands, particularly in a complex society, individuals require knowledge about their relative strengths and weaknesses, and about which features they share with others and which are distinctive - knowledge achievable only through juxtaposition with the opinions and abilities of others. Comparison thus offers the subject a means of orientating and understanding themselves. More recent approaches, while continuing to focus on motivation, have located the impulse in a need to evaluate, in particular to accord positive evaluation to the self. In this perspective, comparison offers possibilities for enhancing self-image, especially where subjects deliberately pursue 'downward comparison' by matching themselves against an inferior (Suls et al. 2002). Researchers' ongoing focus on cognitive motivation clearly has much to do with the disciplinary focus of psychology. But related research agendas more social and political in their focus have emerged also, notably the study of 'relative deprivation' (Runciman 1966).

Let us first consider social comparison from a formal perspective, before thinking about its contemporary manifestations. Clearly not all comparison is 'social'. While a human self of some sort is always present - the author of the 
comparison - the elements of which the comparison itself is composed may be entirely intra-personal or non-human. For example, one can make a crosstemporal comparison with past selves (the 'younger me' with 'today's me'), comparison with an ideal standard ('beauty', 'intelligence', 'morality'), or comparison with a counter-factual self ('me as I am' with 'me as I might have been', or 'me as I experience things here' with 'me as I would experience things there'). Comparison can also involve inanimate beings (a comparison of one law with another). What then is social comparison? As we shall understand it, social comparison has the following structure: it involves a human subject $(\mathrm{X})$ being matched against a target person or persons (the comparator, $\mathrm{Y}$ ) for assessment according to a particular dimension (Z). While the author of the comparison will not always make these terms explicit ${ }^{4}-a$ degree of interpretation tends to be required - it should generally be possible for the observer to narrate the comparison act in these terms.

Probably the first of these terms is the most straightforward. $X$ denotes a human actor of some kind. Evidently it need not include the author of the comparison him / herself. The comparison may be composed entirely of third persons, as when a law-maker considers which of two potential recipients of scarce resources is most deserving, or when a citizen chooses which party to vote for. ${ }^{5}$ First-person comparisons will be our focus, since they have an immediacy and emotional involvement not present when the author detaches him- / herself, but they are only one variety of several. Note also that the subject may appear in singular or plural form - as an ' $\mathrm{I}$ ' or a 'we'. Note further that subjects may come with a certain category attached, e.g. 'we as women', 'we as black people', or 'I as a Muslim'. We shall return to some of the implications of this later.

\footnotetext{
${ }^{4}$ Indeed, there may be cases when one wants to speak of tacit comparisons - those not given explicit articulation at all, yet seemingly implicit in certain acts and utterances.

${ }^{5}$ One of the biases of psychology-informed approaches to social comparison is the way the self and self-esteem tend to be placed centre-stage as a matter of course.
} 
Next in our formal sequence is the comparator, $\mathrm{Y}$ (sometimes termed the 'comparative reference group' - Runciman 1966, p.11). It may be useful to conceive three guises in which the comparator may appear. First (Type 1), it may be an individual who is closely familiar to the subject, probably as a result of repeated encounters. In such cases the subject will have a sizeable body of information about this person, enabling a variety of comparisons, and is likely to think of this person first as an individual and only secondarily as the representative of a social group. ${ }^{6}$ Examples would be friends, family members and colleagues. Second (Type 2), the comparator may again be a really-existing person, but one encountered only briefly or occasionally. The subject therefore has limited information about them, and they remain largely a stranger. They may be associated primarily with a single context and treated either as a social type or, where their individuality is affirmed, as a distantly remembered 'name'. One's hairdresser or bank manager might be examples. Third (Type 3), the comparator may be an idealised type who is simply imagined by the subject. With this comparator there are no moments of co-presence, and they are necessarily thought of in generic terms (and also, therefore, as members of a group rather than as separable individuals). Their existence may be suggested to the subject on the basis of publicly available information (e.g. in the media, in official data, or in political discourse) and anecdotal knowledge or 'popular wisdom', mixed in with ingrained memories of past experiences. In this case the subject is dependent on their imagination and on narratives and knowledge resources external to their own conscious experience.

If one accepts these as analytical distinctions - and clearly there will be empirical instances whose correct assignment to one class or another will be a matter for debate - then one can accord them different kinds of significance.

6 On the way personal ties may foster comparison practices, see Gartrell in Walker and Smith 2002. 
The first kind - based on repeated co-presence - is the most private scenario, and its significance is likely to be local. Regarding the comparator in this way does not involve treating them as a manifestation of a larger context (the point is exactly that the individual is seen as transcending their circumstances) and so the implications of the comparison act are likewise likely to be for the subject as an individual. As regards the second kind - based on rare copresence - much is likely to depend on the contact situation (Pettigrew 1998). There will be contexts in which the comparator's individuality is highlighted, and others where they appear primarily as categories: for example, when there is a clear mediating role relationship (a waiter serving a customer, a boss addressing an employee) which invites the situation to be experienced in stereotyped terms, or sharp markers of difference (e.g. language), or when the encounter is entirely new, with no previous interaction to refer to. Different situations will invite different forms of aspect perception. While in the first case the situation becomes analogous with that based on comparison with familiars, in the latter cases it moves closer to the third kind - comparison not grounded in co-presence. Here, with the comparator knowable only as a category (e.g. the 'worker', 'the Frenchman'), we have arguably the most political scenario. Politics in many of its forms requires people to think of each other in categorical terms - that is, to look beyond the peculiar characteristics of individuals and beyond whatever private connections one might have to them so as to place them in a larger scheme. ${ }^{7}$ Comparisons of this kind facilitate the abstraction which politics requires. They are also political in the sense that they are the site of power relations, since they are

\footnotetext{
7 This is not to overlook that efforts to encourage people not to think in category terms, and instead to personalise or privatise a situation, may themselves be political in character. Consider for example the use of first names by British politicians when referring to their colleagues - a strategy presumably designed to increase perceptions of them as accessible people rather than career politicians.
} 
peculiarly susceptible to manipulation, not being dependent on the subject's personal experiences. ${ }^{8}$

We have introduced $\mathrm{X}$ and $\mathrm{Y}$ as persons, real or imagined. It is worth emphasising however that, even in those cases where they are real, it is not persons in their entirety which can be the currency of comparison. Given the complexity of any individual, they can never be apprehended with equal regard for all dimensions of their existence: comparison involves singling out a certain aspect on which to focus. This brings us to the third of our terms, Z, the dimension or criterion of comparison. This may take various forms: it may relate for instance to a person's circumstances (e.g. their problems or privileges), their skill in a certain task, or their opinions on a certain topic. Where the comparator, $\mathrm{Y}$, is simply an imagined social category, the criterion of comparison may be largely self-evident, since that category may have few dimensions of public significance. Where the comparator is evoked with greater specificity and complexity, and thus permits a wider range of comparisons, the subject will need to exercise discrimination in the dimension they choose. Note that $Z$ can be anchored with respect to an ideal, such that $X$ and $\mathrm{Y}$ are compared for how closely they approximate a transcendental standard, be it a positive one such as 'the moral life' or a negative one such as 'brutality'. Alternatively it can be strictly relative, such that $X$ and $Y$ are compared e.g. for the length of their hair, with no embedded notion that there is an ideal length.

Clearly, some dimensions of comparison will be of greater interest to the political sociologist than others. Facebook invites users to compare their 'friends' according to their looks and their smell, while daily life offers many opportunities to compare personal possessions such as mobile phones. While

${ }^{8}$ Like all forms of common sense, social comparison is both a source of power (the power to normalise) and that which is shaped through power. 
these practices are interesting in a number of ways, particularly from a socialpsychological perspective, their political implications are indirect at best. More interesting in this regard is when the criterion of comparison concerns such non-trivial life circumstances as employment, living conditions, security, relative purchasing power, and so on - dimensions we shall return to shortly.

It is worth emphasising that the act of comparison may lead to varied outcomes. It may produce the affirmation of sameness or equivalence (an outcome our language usage may lead us to expect, in that when we term things 'comparable' we imply not only that they can be compared but that a comparison will lead us to conclude similarity), and a tendency to assimilate $\mathrm{X}$ and Y. Alternatively the outcome may be to affirm difference between the subject and the comparator, and thus to contrast $\mathrm{X}$ and $\mathrm{Y}-$ although such a conclusion still supposes the same metric can be applied to both, and therefore implies a second-order resemblance. In either case, the outcome can be treated as something positive, negative or neutral: it will be ascribed a certain valence. Furthermore, the conclusions drawn may focus on what the comparison indicates about the nature of $X$ (the subject) or the nature of $Y$ (the relevant other). Note, finally, something implicit in what we have said so far (and in the social-psychological distinction between 'upward' and 'downward' comparisons): not all acts of comparison are open-ended in the sense that they have no preconceived outcome. Some are loaded in advance, such that $\mathrm{X}, \mathrm{Y}$ and $\mathrm{Z}$ are chosen so as to affirm something the comparisonmaker wishes to affirm.

These points may be summarised in tabular form: 


\begin{tabular}{|c|c|c|c|c|}
\hline $\begin{array}{l}\text { Elements of } \\
\text { social } \\
\text { comparison }\end{array}$ & $\mathrm{X}$ - the subject & $\mathrm{Y}$ - the comparator & $\begin{array}{l}\mathrm{Z}-\text { the dimension of } \\
\text { comparison }\end{array}$ & Outcome \\
\hline Characteristics & $\begin{array}{l}\text { Here: the first- } \\
\text { person } \\
\text { pronouns, 'I' or } \\
\text { 'we' }\end{array}$ & $\begin{array}{l}\text { Type 1: a real individual, } \\
\text { familiar due to repeated } \\
\text { exposure } \\
\text { Type 2: a real individual, } \\
\text { but known through } \\
\text { limited and context- } \\
\text { specific exposure, hence } \\
\text { associated with just one } \\
\text { or a small number of } \\
\text { roles } \\
\text { Type 3: an imagined } \\
\text { entity, approached as a } \\
\text { social category }\end{array}$ & $\begin{array}{l}\text { Normative (i.e. } \\
\text { connected to an } \\
\text { ideal) } \\
\text { or relative }\end{array}$ & $\begin{array}{l}\text { Affirmation of } \\
\text { similarity or } \\
\text { difference ... } \\
\text { Given positive, } \\
\text { negative or neutral } \\
\text { evaluation }\end{array}$ \\
\hline
\end{tabular}

Why though does social comparison matter? What are the reasons to study it? Arguably it has an intrinsic interest as a distinctive form of social practice, one irreducible to related notions such as 'identity'. Yet its significance goes beyond this. Indeed, much of human understanding has a comparative dimension. This includes, first, an understanding of oneself and one's predicaments. How an individual sees their own experiences will depend in part on how far they have the ability and inclination to place these in a larger context and see them as replicated elsewhere, or how far conversely they see these experiences as mainly specific to themselves. For instance, it matters greatly for a person's self-understanding whether they perceive certain economic difficulties as mainly a distinct, personal challenge or whether they see them as shared, and if the latter with whom they see them as shared and with whom not at all or less so. This may influence the extent to which they see these challenges as 'normal' or unusual, and how far they see them as appropriate targets for collective address or a matter for individual adaptation. 
Note, second, that practices of social comparison may have important implications for the meanings commonly given to concepts with a relational dimension. Notions for instance of poverty, equality, security, risk, quality of life (including living conditions, health, work-leisure balance and the quality of nutrition) and of geographical location (including the status of being peripheral or central) are all to some degree - even if not entirely - relative. What constitutes poverty depends on how one delimits the social field. This has, furthermore, implications for how people distinguish between what is just and unjust, insofar as some types of justice-claim refer to the relative deprivation of groups of citizens rather than to the absolute condition of the individual (Feinberg 1974).

Practices of social comparison may take place even where there is no generalised sense of shared subjecthood of the overarching territorial kind implied by terms such as 'national' or 'European identity', or issue-specific relations of solidarity such as the 'class for itself'. Thicker forms of social integration of this kind are one possible outcome of social comparison, but they are not the same as it. Indeed, there may be places where ties of empathy and solidarity are quite weak yet where practices of comparison are common: the former Yugoslavia would seem a candidate in this regard. Likewise, as a practice of interpretation rather than a material fact, social comparison cannot be assimilated to a positivist conception of shared identity or of the 'class in itself' (both of which take us back towards the realm of system integration). ${ }^{9}$ Social comparison is a distinct category of practice and merits its own investigation.

\footnotetext{
${ }^{9}$ For a typology of forms of collective subjectivity, see Domingues 1995 . Note the configurations evoked through social comparison cannot be subsumed within any one of the types provided, though elements of several may be involved.
} 


\section{Social Comparison in the Transnational Setting}

What impact might the institutional changes associated with European integration have on practices of social comparison? Without itemising these system changes in detail - their particularities are in any case in flux - we can make the guiding assumption that they create new opportunities for social comparison and increase the likelihood it will take cross-national form. In the most general sense, this is because conditions of instability and change are always likely to be those which prompt recourse to comparison, since such conditions are disorienting and place the traditional scheme of things in doubt. It is when people become uncertain of their circumstances and status that they may be most impelled to seek reorientation through comparison. But there are also more specific grounds for seeing these processes of change as conducive to social comparison. Let us examine a few of them.

First, these processes of system integration generate new kinds of social encounter, and thus new situations inviting social comparison. They contribute to many of the 'mobilities' identifiable amongst contemporary Europeans (Urry 2007, pp.10-11). Prominent amongst these are those associated with temporary employment migration, tourist trips, family visits, the adventure-seeking travel of young people, travel for the purpose of receiving medical care, and long-term relocation for employment or retirement reasons. Some such movements will lead to in-depth crossnational acquaintanceships of the kind that invite Type 1 social comparisons. Think for example of a chance encounter between students while InterRailing, developed into stronger attachments in the course of time spent travelling together, and later kept alive using a virtual network such as 
Facebook. Think likewise of the Erasmus exchange. ${ }^{10}$ As noted, these may not be the source of the most politically-interesting forms of social comparison, insofar as they generate mainly personal connections, but they are stimuli nonetheless. Of course, many such forms of mobility will not result in thick, repeated interactions but in one-off or occasional moments of co-presence: in this sense they may be conducive to Type 2 social comparisons. Modern life in general affords many such sites of encounter where strangers are brought together, from the metro carriage and the busstop to the shopping mall and the museum (Urry 2007, p.37). Transnational integration, insofar as it intensifies cross-border movement, heightens the centrality of sites bringing together a potentially even more diverse set of strangers: the hotel, the airport, the beach, the carriage of the trans-continental train, the bars and clubs favoured by travellers and stag-nights, the (internationalised) university library and canteen, the football stadium, and the passport control queue.

One must be cautious in conceiving the wider significance of such encounters. The guise in which people appear to one another in such locations may be quite site-specific: e.g. as the fellow passenger, the fellow shopper, the fellow drinker. Insofar as comparisons are provoked, they may be specific to the social categories associated with these situations: for instance, the beach may invite comparisons of beachwear, body shape and suntan, and the football stadium those of intensity of support and richness of chants - criteria potentially of little relevance to other social settings. But one can assume that such sites provoke other comparisons whose significance is transferable: a comparison of what fellow commuters are reading with one's own reading matter may lead to wider assessments of the relative sophistication and

\footnotetext{
${ }^{10}$ Encounters stemming from the Erasmus programme certainly need not lead to a heightened sense of 'European identity' - cf. Sigalas 2010 - but may still contribute to a broadening of the scope of social comparison.
} 
awareness of ones fellows, comparisons of considerable significance for the individual's understanding of the world around them and their place within it. Likewise the passport control queue, which evokes and institutionalises hierarchies, and invites citizenship-, culture- and class-related comparisons, has a significance beyond itself. ${ }^{11}$ Even the airport baggage reclaim, which seems to invite little more than a comparison of suitcases, may potentially be a rich source of class- and taste-related comparisons liable to become entwined with comparisons made in other locations.

An extension of the sites of everyday social encounter represents just one of the relevant consequences of transnational integration. Potentially of greater political significance is the way it invites Type 3 social comparison, involving the evocation of those with whom there are no moments of co-presence. The evocation of these hypothesised or 'imagined' comparators is fostered first by the standardisation of experience which system integration entails. With the development of the EU, Europeans have been exposed to common legislation (where there are harmonised EU rules) or to legislation which, though different from one country to the next, is designed to meet common objectives. Common quality standards on consumer goods, or the single currency, are obvious examples. Insofar as legal integration entails an extension of (imagined) common experiences before the law, it seems likely to foster the conditions in which comparison presents itself as plausible, and to foster the conjuring of comparators abroad whose experiences bring those of the subject into relief. In the absence of a larger common framework, the social world beyond the nation-state presents itself as 'apples' to the nation's 'oranges', and therefore as an inappropriate target of comparison. Legal

11 Cf. Urry 2007 p.151 and Aaltola 2005 as cited. 
harmonisation changes this. ${ }^{12}$ Moreover, system integration makes possible not just one or a series of unrelated dimensions of comparison but dimensions which present themselves in clusters. One of the best established findings in social comparison research is that individuals are most inclined to compare their personal circumstances with those of people they consider broadly similar to themselves as judged on secondary factors presumed relevant to the dimension in question (Festinger 1954). For example, a comparison of earnings is likely to be of interest to an individual only if there is perceived similarity with the comparator on related dimensions (e.g. age, job type or level of education), something which requires that for every one dimension (Z) it be possible to imagine other dimensions plausibly in correlation with it. By making several of these susceptible to measurement on single, panEuropean scales, EU integration invites them to be invoked in conjunction with each other, thus raising the appeal of any single comparative dimension.

Of course, transnational integration does not necessarily produce these outcomes, since it also has countervailing dynamics. One of its consequences, before the effects of common legislation are felt, may be to expose people to greater extremes. Think, for instance, of the migrant labourer who changes his reference groups while living abroad, and who unwittingly provides material for a new reference group both for those in the host society and those in the country of origin. For criteria of comparison such as wages or living conditions, such individuals may introduce new levels of variation. At best this may produce an assertion of difference - albeit one that supposes, as noted, sufficient similarity to apply the common metric by which difference can be observed. Just as plausibly it may encourage a retreat into narrower

\footnotetext{
12 The plausibility of comparison is likely to be deemed all the stronger where interdependence between subject and comparator is assumed: where, in other words, the circumstances of the comparator are considered not just equivalent to those of the subject but connected.
} 
forms of comparison and a rejection of those that highlight wide discrepancies. We shall return to this point in due course.

The mere presumption on the subject's part that the experiences of distant strangers are of relevance is likely to be strongest where it has a basis in fact. The question then is whether transnational integration comes accompanied by the availability of information which can give foundation to comparisons. One thinks for instance of quantitative data of the kind which evokes social groups across European space as statistical categories - the kind of anonymous comparators one can associate with Type 3 comparison. ${ }^{13}$ There are a wide range of criteria for which cross-national data can be collected: data which affords comparison for instance of prices and purchasing power, of earnings across different employment sectors, of taxation rates for different income groups, of public spending in different policy sectors, of crime trends, and so on. Information of this kind is collected by countries around the world, and the possibility of drawing on it to make cross-national comparisons is hardly a novel phenomenon. But as comparativist social scientists have often been the first to discover, making cross-national comparisons on the basis of data aggregated separately in different countries can be highly problematic, since the methods used to collect it in different places may be quite dissimilar, and the categories used to organise it may have quite different thresholds of inclusion. The measurement of poverty and inequality is a classic instance: those classed as 'poor' in one country may be very much better off than those classed as poor in another (Fahey 2010). ${ }^{14}$

\footnotetext{
13 While quantitative data especially lends itself to this, there may be plenty of qualitative empirical comparisons to be made too, e.g. of the fortunes of different party families from one country to the next.

${ }^{14}$ Cf. Fahey 2010, p.12: 'in the UK, a single person household with an income of 11,000 PPS would be counted as poor (just below the UK poverty threshold of 11,366), while a similar household with the same income in Poland would be counted as well off in that they would have almost double the Polish median of 5,703 PPS. Many of the poor in Britain thus have higher living standards than the Polish middle classes, not to mind the Polish poor, so that it might reasonably
} 
What presents itself as a single criterion of comparison may in fact therefore be a compound of two, and while such data may continue erroneously to be drawn on for comparison purposes, when their limitations become known they are likely to be rejected and perhaps the very possibility of comparison questioned. One of the interesting implications of EU integration is the possibility it holds for the collection of data organised at a transnational level using a pan-European scale - a possibility the Commission has sought to take advantage of as it makes moves to replace a series of national benchmarks with an indicator of material deprivation expressed in pan-EU terms. An ongoing debate in social-policy research concerns whether the European frame of reference is the most appropriate or whether the national should remain the default one - a question which can be answered with appeal to a variety of criteria, including policy relevance, the observer's assessment of what is objectively valid, and the standards that citizens themselves use (Fahey 2010) (Whelan and Maitre 2009). There is no definitive answer - each is an act of interpretation, as well as a move with political implications - but let us simply note that where the European option is chosen it provides a further knowledge resource for those tempted to engage in practices of crossnational comparison.

Clearly, where factual information of this kind is taken up in the media, its public diffusion is likely to be greater. Relevant instances are not difficult to find. As a country low on 'European identity', Britain makes a critical case. Its print media shows a willingness to run stories based entirely on how Britain compares to specific other European countries or a European average along a particular dimension, in some cases drawing directly on Eurostat data, in others cases on private sources. Many of these stories have a 'bad

be asked whether there is any sense in which the extent and nature of poverty in these two contexts might need to be captured somewhat differently.' 
news' flavour, with the article's key point being that Britain does worse than its comparator(s) with respect to the criterion in question - that it 'tops the league', be it the 'jobless league'15, the 'crime league'16 or the 'divorce league'. ${ }^{17}$ Likewise an article in the German media which, drawing on Eurostat data, reports 'Bad Marks for Germany on Women's Pay'. ${ }^{18}$ Even that most eurosceptic of outlets, the British Daily Mail, has run stories premised on the relevance of cross-national comparisons and well stocked with empirical data on the 'European average': 'Let's all go to France!', was one writer's suggestion, 'British quality of life can't compare to the continent'. ${ }^{19}$ Note that the subject of these comparisons continues to be framed in national terms: it is 'Britain', 'Germany' etc. which is being compared to other countries, not particular sub-groups with other sub-groups - even if the comparisons could easily be reframed in these terms (as in the case of gender disadvantage).$^{20}$ Note also the imagery of the 'league', which invites the dimension of comparison to be seen in purely relational terms without an anchoring ideal standard.

There have been fairly few studies of whether lay practices of social comparison amongst Europeans are likewise prone to include cross-national elements. Some researchers have attempted to explore this with opinion polls, notably (Delhey and Kohler 2006), where the focus is on levels of life

\footnotetext{
${ }^{15}$ www.independent.co.uk/news/uk/home-news/britain-tops-jobless-league-table2103407.html

$\frac{216}{16}$ ww.telegraph.co.uk/news/uknews/1541699/Britain-tops-European-crime-league.html

${ }_{17}$ www.independent.co.uk/news/uk/this-britain/divorce-rate-falls-but-uk-still-tops-european-league673779.html

${ }_{18}$ www.spiegel.de/international/europe/0,1518,476658,00.html

19 www.dailymail.co.uk/news/article-1314112/France--Lets-British-quality-life-comparecontinent.html.

${ }^{20}$ Nonetheless, one can find examples which, even if still based on cross-national comparison, are not focused on the experience of one particular nation in comparison to others. See for example a different kind of reporting of Europe's 'gender pay gap' in the Guardian (www.guardian.co.uk/money/2007/jul/18/pay.business) and BBC (http://news.bbc.co.uk/1/hi/6904434.stm). See also the Guardian's 'Europe season' (from 14th March 2011), which encouraged readers to learn how their 'neighbours' Germany, France, Spain and Poland respond to a common set of everyday social and political challenges (www.guardian.co.uk/world/2011/mar/13/germany-guardian-new-europe-series).
} 
satisfaction. Their research finds that, amongst the population groups studied (Turkey, Hungary, Western and Eastern Germany), 75\% of respondents, when asked to assess their own standard of living, made cross-national comparisons in addition to those with friends, neighbours and co-nationals. The possible range of comparators was set by the survey designers in advance: they do not include all EU and European countries, nor do they feature countries beyond Europe (the list being: Switzerland, Netherlands, Sweden, France, Poland, Spain, Italy, Hungary and Germany). While this limits what we can infer about the content of cross-national comparisons - in particular, whether the respondent wishes to emphasise circumstances in specifically these countries, and how far one can speak of a 'europeanisation' of reference groups rather than a few targeted, 'bilateral' references to specific country groups - it nonetheless suggests an assumption of the national boundedness of comparison practices is problematic.

The point comes through also in qualitative research. ${ }^{21}$ In a study conducted by the author (White 2011; 2009), group interviews with citizens in Germany, Britain and the Czech Republic concerning a range of everyday problems (e.g. high and rising prices, low wages) produced a number of spontaneous crossnational comparisons. One of the study's suggested findings is that, in line with the above, the range of comparators is likely to vary according to the criterion of comparison (i.e. where $Z$ changes, so one can expect $Y$ to change). Whereas economic issues tend to produce comparisons with neighbouring European countries (but not necessarily Europe as a whole), issues to do with intergroup relations (e.g. the ability to successfully integrate immigrants) tend to provoke a wider range of comparators more broadly associated with the

\footnotetext{
21 For an interesting study of how the EU is taught in French schools, see Bozec 2010, including p.168 for observations on how teacher-led initiatives to establish pen-pal links with schools in Poland, Germany and Spain led to practices of cross-national social comparison amongst pupils. See also the autobiographical narratives of Europe's highly mobile 'eurostars' in Favell 2008, many of which display elements of social comparison (see chapter 1 for early examples).
} 
'West'. Issues of law and order, by contrast, tend to produce few crossnational comparisons - probably because such issues are seen as local in their origins and effects. At least for the medium term, rather than a generalised trend towards Europe-wide practices of comparison, it seems most plausible to expect a series of spheres whose extension varies from one issue domain to the next.

\section{Implications of an Enlarging Scope of Comparison}

So far we have examined the formal structure of social comparison, some of the reasons to expect its evolution to include cross-national dimensions, and the existing research that has looked into this. Insofar as such developments are real, what implications might they hold for social integration in Europe more generally, beyond the widening horizons of awareness and perceived relevance that social comparison signals? What are the likely consequences of an enlarging scope of comparison? We shall tackle this question at the level of lay citizens, though clearly a parallel line of research would involve posing it at the level of political and economic elites. In either case, what interests us is to identify some of the patterned sequences social comparison may give rise to, even if - as with social mechanisms generally - these are various, possibly contradictory, and the pre-eminence of one over another is not to be determined ex ante.

Evidently one likely consequence of wider comparison is the recalibration of people's sense of their own social position. System integration introduces a whole new range of comparators. Exposed to a wider variety of human experiences in Europe, people may come to rethink how they stand relative to others. Those who see themselves as of low economic or social status, 
confronted with the yet worse circumstances of those elsewhere, may come to rethink themselves as part of a 'comfortable middle'. Those of high status in a local setting (e.g. the provincial businessman, or the stand-out student of the local university) may come to question their superiority. In other words, by offering new points of comparison, the cross-national context prompts revisions to existing practices of comparison. The proverbial big fish may be recast as modest fare, just as the small fish is revealed to be not so minor after all. ${ }^{22}$ This may be a disorienting and distressing process for some, as a sudden reappraisal can prompt feelings of humiliation, but in principle one would expect it to be a positive experience for others. New feelings of relative deprivation might be counter-balanced by new feelings of 'relative gratification' as it has been called (Pettigrew 2002). This twin dynamic is foreseeable even at the intra-personal level, as shifts on one dimension of comparison are compensated by shifts on another. If this process of reappraisal were engaged in by all equally, one would expect something approaching an overall balance in the numbers of those who came to reassess themselves positively or negatively - the process would be 'zero-sum' in its reallocation of self-worth. ${ }^{23}$

But here lies the crux: such symmetry of practice seems unlikely. Social comparison, it has been suggested, is pursued with most urgency by those who sense or fear that in relative terms they are not doing well. Those who are comfortably off (by whatever criterion) may be less aware of their

\footnotetext{
22 Note also that European integration has the potential to generate new criteria of comparison (Z) which produce new scales of advantage and disadvantage - e.g. to do with the ability to access the benefits of integration itself. The very novelty of these dimensions may give them added levels of public resonance.

23 For an overview of different emotional responses to social comparison, see Smith in Suls and Wheeler 2000, esp. p.176, which describes four basic variants: downward-assimilative comparisons (producing shared concerns and sympathy), downwards-contrastive (with contempt / Schadenfreude / self-satisfaction), upward-contrastive (with envy / depression) and upward-assimilative (with admiration / inspiration / optimism).
} 
advantage, and less concerned to verify it, than are those less well off. ${ }^{24}$ The latter have added incentive to engage in comparison, whether to learn more about their predicament or to console themselves with the knowledge that it is shared, perhaps even experienced more severely elsewhere. ${ }^{25}$ This would suggest a preponderance of cross-national comparisons amongst those who, in the existing order, feel aggrieved or insecure - e.g. the poor in a wealthy, west-European country, or the poor and middle classes in a medium-to-poor central- / east- or south-European country. It would likewise suggest particular attentiveness to those dimensions $(Z)$ on which the subject is thought to fare badly (an impulse which the league-table examples above seem to appeal to). Furthermore, 'upward' comparisons - those which establish or are premised on the superiority of the comparator's circumstances over those of the subject - may be the ones which lodge themselves most firmly in the subject's imagination. If there is asymmetry in the comparisons pursued, it would seem to suggest the following proposition:

1) Cross-national social comparisons tend at the aggregate level to increase perceptions of relative deprivation without a corresponding increase in perceptions of relative advantage.

European integration would, in other words, make Europeans on balance feel a little bit worse about themselves. ${ }^{26}$

Let us leave aside the normative issues this raises - whether for example popular dissatisfaction of this kind, based on relative rather than absolute appraisal, is something one should want to avoid or whether it can be a

\footnotetext{
${ }^{24}$ Cf. Walker and Smith p.137 on the idea that the advantaged tend to take their advantage for granted, and tend to be weakly inclined to see themselves as part of an advantaged group.

25 This point needs to be balanced against the fact that expectations may be higher amongst highstatus groups (and disappointments thus correspondingly stronger), as well as the likelihood that factual knowledge about other locations is higher amongst these groups.

26 This will be all the more true if there is a dynamic dimension to the appraisal, such that 'our' condition is said not just to be bad but deteriorating.
} 
source of inspiration for positive political change and thus a valuable component of citizenship. Let us focus instead on the sufficiently complex political-sociological dimensions. If heightened perceptions of relative deprivation are a predictable outcome of cross-national social comparison, one might infer two plausible but opposed conclusions. On the one hand one might see comparisons as generative of heightened levels of individual stress for which individual solutions are sought. Such an outcome could take several forms: it could entail feelings of resentment towards those whom comparisons reveal to be advantaged; efforts to rationalise the discrepancy e.g. by appeal to notions of merit; moves to close the gap through individual adaptation; an inclination to retreat from wider social commitments so as to minimise the adverse feelings they produce; or a tendency to deny the feasibility of cross-national comparison, or to switch the dimension of comparison $(Z)$ so as to produce more favourable results (e.g. to renounce a prosperity criterion in favour of a morality one - 'they' are rich, but ' $\mathrm{I}$ ' / 'we' are good). ${ }^{27}$ One is reminded of Elster's description of the 'sour grapes' phenomenon, a classic strategy for coping with dissatisfaction (Elster 1985). In the short to medium term, cross-national comparisons would then seem to have few destabilising political consequences. Indeed, insofar as they relativise experiences (e.g. of poverty) by showing how there is 'always someone worse off', they may produce apathy and prove actively immobilising. ${ }^{28}$ Still, in the longer term, this tendency could be expected to have subversive consequences, as it might easily entail the slow ebbing of support for the very institutional frameworks which prompt these

27 A retreat from social comparison may be accentuated insofar as integration exposes individuals to those whose preferred criteria of assessment are different from their own, and who thus serve to undermine the validity of the reference criteria hitherto invoked - a variation of Durkheim's anomie.

28 This effect is accentuated insofar as integration exposes individuals to those prioritising criteria of assessment different from their own, and who thus undermine the validity of the reference criteria hitherto invoked. 
unfavourable comparisons. The EU's political legitimacy would in this way be weakened.

Yet there is a counter-tendency one might also foresee: an emergent awareness of personal disadvantage spurring moves to seek out others who share in this predicament, perhaps so as to make common cause. The initial act of social comparison which reveals relative disadvantage, and which therefore has an unsettling character, would thus be coupled with a second one that re-embeds the individual in a larger collective and forms the basis for an enlarged sense of 'we'. In this scenario, social comparison fosters the emergence of new bonds of solidarity and cross-national subjecthood. It enables moves towards the emergence of classes for themselves, as the familiar terminology has it (though classes in the broad, not necessarily economic, sense). This way lies the transnationalisation of social cleavages and potentially their politicisation at a European level. Insofar as these forms of subjecthood translate into specific political demands, one could expect them to impinge on the institutional structure of the EU and its legal order in the form of pressure for its redesign - i.e. to have fairly immediate consequences for system integration. Protest movements, including contemporary ones against the 'austerity' programmes being pushed by governments across Europe, involve efforts to evoke a popular sense of equivalence with precisely such goals in mind, and when their organisers acknowledge the inspiration of counterparts abroad they themselves are testifying to the mobilisatory capacity of the comparative logic. ${ }^{29}$

Again, for clarity's sake, we can express these alternatives in propositional form:

${ }^{29}$ On British student protesters taking inspiration from Spain, see http://www.guardian.co.uk/world/2011/jun/20/student-walkouts-public-sector-strikes. 
2a) The adaptation thesis: when cross-national social comparisons heighten perceptions of relative deprivation, citizens will look for narratives that can rationalise this, and / or make individual efforts to change their relative standing, and / or resist the making of comparisons, and / or seek to restructure them in more favourable ways.

2b) The mobilisation thesis: when cross-national social comparisons heighten perceptions of relative deprivation, citizens will seek out and make common cause with those revealed to be similarly disadvantaged.

Here is not the place to settle the matter, but perhaps the following can be noted. Scholars of relative deprivation make a potentially relevant distinction concerning how the comparison subject (figure $X$ in our typology) comes to be articulated. When a speaker presents their sense of comparative disadvantage using the first person singular, ' $\mathrm{I}$ ', this may be referred to as personal deprivation: it is as an individual that the subject feels deprived. When a speaker presents the matter using the first person plural 'we', this may be thought of as group deprivation: it is as part of a collective that the subject feels deprived (Walker and Smith 2002). ${ }^{30}$ Both can be a basis for comparison, but the consequences of the first are likely to be mainly psychological and local - e.g. individual displeasure, and perhaps an individual effort to improve relative standing - rather than an organised effort to find collective voice. The consequences of the second on the other hand may be wider in scope and more likely to bring social change: comparisons formulated in this way suggest that individual responses are inappropriate, and suggest the possibility of common cause. This would suggest that, as a minimum condition for orchestrated efforts at wider change, the subject's comparison of their circumstances with those of cross-national

30 Runciman 1966, pp.31ff., makes a related distinction between egoistic and fraternalist deprivation. 
others must take the form of a comparison of 'people like us', not merely of 'individuals like me'. In contemporary Europe, this disposition hardly seems extinguished, but must contend nevertheless with a tendency in public discourse to individualise the citizen, and to acknowledge political demands primarily in the form of individual rights (White 2009, 2010).

Much is also likely to depend on whether the discrepancies which social comparison reveals are held to be remediable or unavoidable. For even where there is a sense of collective deprivation, this may produce no more than silent acquiescence if it is felt to be rooted in immutable conditions. ${ }^{31}$ There needs to be the sense that tomorrow can be better than today. The implications of social comparison are inseparable from the wider political narratives by which those comparisons and their meaning are shaped (White 2011). There is an interesting interplay here between social comparison and perceptions of agency. On the one hand, it is through comparisons that the space for agency can be opened, since those which highlight the variety of human experience show the ways in which things could be different - e.g. the different ways in which public services can be organised and financed. Encouraging comparisons is one way of affirming the possibility of alternatives and reducing political acquiescence. On the other hand, comparisons unaccompanied by a narrative about the possibility of realising these alternatives, 'here' as much as 'there', may rather provoke envy or demoralisation. In all these aspects one sees the dimension of power: those who shape these wider narratives, be they partisan actors in the parliamentary sphere or the media, have considerable influence over the extent to which the fruits of comparison are resignation or agitation. Their ability to 'nudge' people towards a certain comparator (Sunstein and Thaler

${ }^{31}$ Note the fourth dimension of Runciman's definition (p.10): '[...] A is relatively deprived of X when (i) he does not have X, (ii) he sees some other person or persons [...] as having X (whether this is or will be in fact the case), (iii) he wants $X$, and (iv) he sees it as feasible that he should have X.' 
2008), and to influence how the comparison act is interpreted, is a notable source of power.

\section{Conclusion}

This paper has examined how processes of system integration at the transnational level present new opportunities for the practices of social comparison. By generating diverse social encounters, new information resources, and an extension in the scope of common legislation, these processes invite citizens to compare their daily experiences with those of people further afield and to evoke reference groups outside their country of residence. Conceptions e.g. of economic hardship - who experiences it, who escapes it - have the potential thereby to draw in reference-points beyond the boundaries of the nation-state. Drawing on findings from recent research, the paper has discussed how far, and when, such possibilities are likely to be realised, and the potential political significance of these practices.

To what extent should the comparison act be seen as a contribution to social integration? Clearly we are dealing with something much less demanding than is implied by notions of common identity. The structure of social comparison asserts the fact that the subject and comparator are ontologically separable, even if deemed to be similar - and any assertion of similarity is always specific to a particular metric of comparison. At the same time social comparison may form the basis for the emergence of thicker ties. Stronger bonds of collectivity may well demand the prior recognition of an equivalence of social position, as well as the motivation to find common cause that a sense of injustice promotes. By widening public conceptions of social and political space, and underscoring similarities and discrepancies of experience, 
comparisons offer an enabling context for this. They offer the basis on which further political narratives may draw. However, though they may be a necessary condition of deeper social integration, they are hardly a sufficient one. In some forms they may have the opposite effect of causing political disengagement and the rejection of the institutional arrangements that enable them. Comparisons can be divisive as well as integrative. Their ultimate contribution will depend as much on the kind of comparisons citizens are invited to make and the conclusions they are encouraged to draw - factors inseparable from larger efforts to shape the contours of political commonsense.

Let us conclude with some observations on what cross-national comparison implies for the continuing hold of the nation-state as the reference-point for popular self-understanding. As we have indicated, the subject $(X)$ and comparator $(\mathrm{Y})$ of social comparison need in no way be denominated using national categories: numerous alternatives are possible (professional, genderbased, generational, etc.), and when these are invoked there is no reason to suppose their frame of reference will be domestic to the national sphere. Social comparison thereby reduces the salience of national boundaries, even without putting them in question. Where comparisons do refer to the national unit (think of the league-tables mentioned), a twin process is at work: the relevance of the national unit is reaffirmed, yet it is simultaneously placed in a larger frame, inviting the citizen to step back to adopt a broader perspective. National boundaries remain a landmark, but no longer form the horizon. Social comparison thus effects a shift in their status. In doing so, it may also put strain on some varieties of nationalist thought. Social comparison can have an unsettling quality, placing established ideas of status in question, and undermining notions of the privileged self. It makes a precarious underpinning for national pride. Furthermore, as we have seen 
with parts of the British media, comparisons may come more easily with those neighbouring European countries held in little affection than with those more distant countries (e.g. the US) with whom such outlets actively promote popular identification. Such discrepancies are logically tenable, but require a double gaze that may be difficult to sustain. They remind at the same time that there is a multi-dimensionality to even the most Eurosceptic orientations, one that would be missed if one focused exclusively on practices of identification. 


\section{References}

Aaltola, Mika (2005), 'The international airport: the hub-and-spoke pedagogy of the American Empire', Global Networks 5 (3), pp.261-78.

Bozec, Géraldine (2010), 'L'Europe au tableau noir: Comment les instituteurs français enseignent-ils l'Union européene aujourd'hui?', Politique Européene 30, pp.153-86.

Delanty, Gerard and Chris Rumford (2005), Rethinking Europe: social theory and the implications of Europeanization (London: Routledge).

Domingues, Jose M.(1995), Sociological Theory and Collective Subjectivity. (London: Macmillan).

Elster, Jon (2007), Explaining Social Behaviour: More Nuts and Bolts for the Social Sciences (Cambridge: CUP).

---(1989), Nuts and Bolts for the Social Sciences (Cambridge: CUP).

--- (1985), Sour Grapes: Studies in the subversion of rationality (Cambridge: CUP).

Fahey, Tony (2010), 'Poverty and the Two Concepts of Relative Deprivation', UCD School of Applied Social Science Working Paper Series WP10/1.

Favell, Adrian (2008), Eurostars and Eurocities: Free Movement and Mobility in an Integrating Europe (Oxford: Blackwell).

Festinger, Leon (1954), 'A Theory of Social Comparison Processes', Human Relations 7.

Guimond, Serge (ed.), (2006), Social Comparison and Social Psychology: Understanding Cognition, Intergroup Relations and Culture (Cambridge: CUP).

Hedström, Peter and Richard Swedberg (eds.) (1998), Social Mechanisms: An Analytical Approach to Social Theory (Oxford: OUP).

Joas, Hans and Wolfgang Knöbl (2009), Social Theory: Twenty Introductory Lectures (Cambridge: CUP).

Lockwood, David (1964), 'Social Integration and System Integration' in G. K. Zollschan and H.W. Hirsch (eds.) Social Change: Explorations, Diagnoses and Conjectures. (Cambridge MA: Schenkman).

Masters, John and William Smith (eds.) (1987), Social comparison, social justice, and relative deprivation: theoretical, empirical, and policy perspectives (Hillsdale, N.J.: Lawrence Erlbaum Associates).

Mouzelis, Nicos (2008), Modern and Post-Modern Social Theorizing (Cambridge: CUP).

Pettigrew, Thomas F. (1998), 'Intergroup Contact Theory', Annual Review of Psychology 49, pp.65-85.

--- (2002), 'Summing up: Relative deprivation as a key social psychological concept', in Walker and Smith (eds.) Relative Deprivation (Cambridge: CUP).

Runciman, W.G. (1996), Relative deprivation and social justice: a study of attitudes to social inequality in twentieth-century England (London: Routledge \& Kegan Paul). 
Sigalas, Emmanuel (2010), 'Cross-border mobility and European identity: The effectiveness of intergroup contact during the ERASMUS year abroad', European Union Politics, 11(2) pp.241-265.

Suls, J. and L. Wheeler (eds.) (2000) Handbook of Social Comparison. Theory and Research (New York: Kluwer Academic/Plenum).

Thaler, Richard H. and Cass R. Sunstein (2008), Nudge: Improving Decisions about Health, Wealth and Happiness (New Haven: Yale UP).

Urry, John (2007), Mobilities (Cambridge: Polity).

Walker, I. and H. Smith (eds.) (2002), Relative Deprivation. Specification, development and integration. (Cambridge: CUP).

Whelan, Christopher T. and Bertrand Maître (2009), "The "Europeanisation" of Reference Groups', European Societies 11 (2), pp.283-309.

White, Jonathan (2011), Political Allegiance after European Integration (Basingstoke: Palgrave Macmillan).

--- (2010), 'European Integration by Daylight', Comparative European Politics 8 (1), pp.55-73.

--- (2009), 'Thematization and Collective Positioning in Everyday Political Talk', British Journal of Political Science 39 (4), pp.699-709. 
Parallel Lives

Eqs 


\section{Recent LEQS papers}

Meyer, Niclas. 'Political Contestation in the Shadow of Hierarchy' LEQS Paper No. 46, January 2012

Hyman, Richard. 'Trade Unions, Lisbon and Europe 2020: From Dream to Nightmare' LEQS Paper No. 45, December 2011

Wagner, Peter. 'The democratic crisis of capitalism: Reflections on political and economic modernity in Europe' LEQS Paper No. 44, December 2011

Chalmers, Damian \& Chaves, Mariana. 'The Reference Points of EU Judicial Politics' LEQS Paper No. 43, September 2011

Hassel, Anke. 'The paradox of liberalization - Understanding dualism and the recovery of the German political economy' LEQS Paper No. 42, September 2011

Hancké, Bob. 'Endogenous Coordination: Multinational Companies and the Production of Collective Goods in Central and Eastern Europe' LEQS Paper No. 41, August 2011

Crescenzi, Riccardo, De Filippis, Fabrizio \& Pierangeli, Fabio. 'In tandem for cohesion? Synergies and conflicts between regional and agricultural policies of the European Union' LEQS Paper No. 40, July 2011

Somek, Alexander. 'The Social Question in a Transnational Context' LEQS Paper No. 39, June 2011

Mabbett, Deborah. 'A Rights Revolution in Europe? Regulatory and judicial approaches to nondiscrimination in insurance' LEQS Paper No. 38, May 2011

Karaman, K. Kıvanç \& Pamuk, Şevket. 'Different Paths to the Modern State in Europe: The interaction between domestic political economy and interstate competition.' LEQS Paper No. 37, May 2011

Scharpf, Fritz W.. 'Monetary Union, Fiscal Crisis and the Preemption of Democracy.' Paper presented at the LEQS Annual Lecture 'Saving the Euro - at the expense of democracy in Europe?' on 12 May 2011 at the London School of Economics, LEQS Paper No. 36, May 2011

Zigante, Valentina. 'Assessing Welfare Effects of the European Choice Agenda: The case of health care in the United Kingdom.' LEQS Paper No. 35, May 2011

Hobolth, Mogens. 'European visa cooperation: interest politics and regional imagined communities.' LEQS Paper No. 34, May 2011

Monastiriotis, Vassilis. 'Regional Growth Dynamics in Central and Eastern Europe.' LEQS Paper No. 33, April 2011

Johnston, Alison. 'The Revenge of Baumol's Cost Disease?: Monetary Union and the Rise of Public Sector Wage Inflation.' LEQS Paper No. 32, March 2011

Glendinning, Simon. “Europe, for example.' LEQS Paper No. 31, March 2011

Winkler, Heinrich August. 'Greatness and Limits of the West. The History of an Unfinished Project.' LEQS Paper No. 30, February 2011

Dani, Marco. 'Assembling the fractured European consumer.' LEQS Paper No. 29, January 2011 
LEQS

European Institute London School of Economics Houghton Street WC2A 2AE London

Email: euroinst.LEQS@lse.ac.uk

http://www2.lse.ac.uk/europeanInstitute/LEQS/Home.aspx

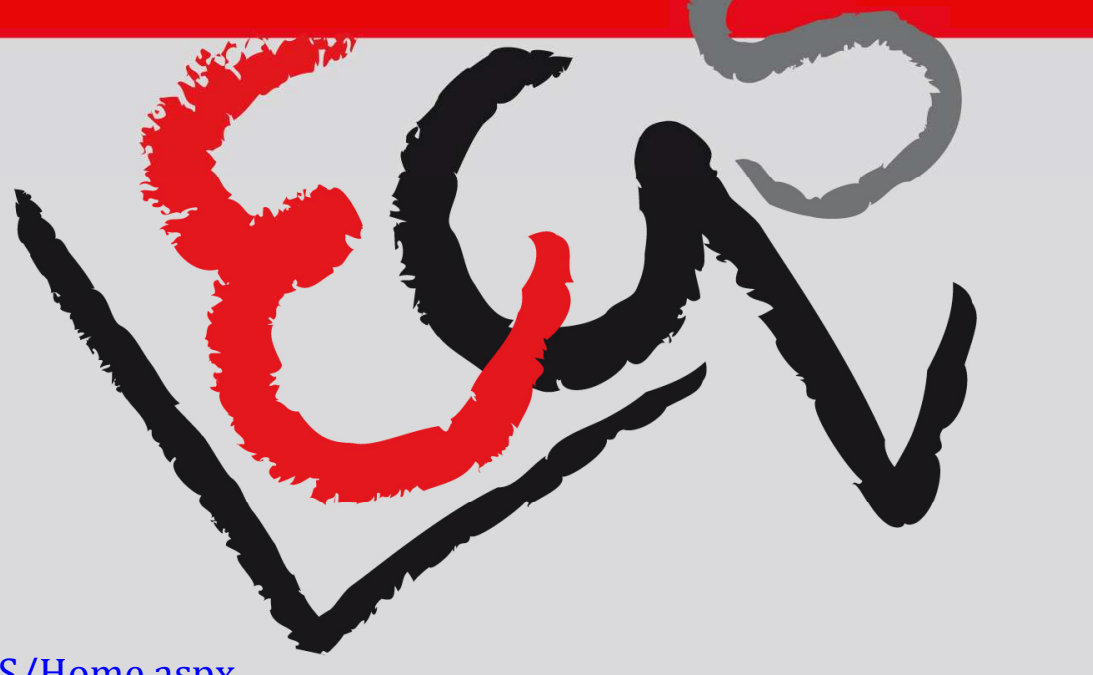

